\title{
Hempel on scientific understanding
}

\author{
Xingming $\mathrm{Hu}$ \\ Philosophy Department, Nanjing University, China
}

\section{A R T I C L E I N F O}

\section{Keywords:}

Understanding

Explanation

D-N model

Hempel

\begin{abstract}
A B S T R A C T
Hempel seems to hold the following three views: (H1) Understanding is pragmatic/relativistic: Whether one understands why X happened in terms of Explanation E depends on one's beliefs and cognitive abilities; (H2) Whether a scientific explanation is good, just like whether a mathematical proof is good, is a nonpragmatic and objective issue independent of the beliefs or cognitive abilities of individuals; (H3) The goal of scientific explanation is understanding: A good scientific explanation is the one that provides understanding. Apparently, $\mathrm{H} 1, \mathrm{H} 2$, and $\mathrm{H} 3$ cannot be all true. Some philosophers think that Hempel is inconsistent, while some others claim that Hempel does not actually hold H3. I argue that Hempel does hold H3 and that he can consistently hold all of H1, $\mathrm{H} 2$, and $\mathrm{H} 3$ if he endorses what I call the "understanding argument." I also show how attributing the understanding argument to Hempel can make more sense of his D-N model and his philosophical analysis of the pragmatic aspects of scientific explanation.
\end{abstract}

Carl Hempel (1965) is well known for holding the following two views: (H1) Understanding is pragmatic/relativistic in the following sense: Whether one understands why $\mathrm{P}$ happened in terms of Explanation E depends on one's beliefs and cognitive abilities. Thus, a scientific explanation that enables S1 to understand might fail to enable S2 to understand. (H2) Whether a scientific explanation is good, just like whether a mathematical proof is good, is a nonpragmatic/objective issue. It is independent of the beliefs and cognitive abilities of individuals. For example, whether Einstein's explanation of the photoelectric effect is good is independent of my or your beliefs and cognitive abilities. It is an objective issue.

However, Hempel seems to also hold (H3), that the goal of scientific explanation is understanding: A good scientific explanation is the one that provides understanding. He writes, "All scientific explanation ... seeks to provide a systematic understanding of empirical phenomena by showing that they fit into a nomic nexus" (Hempel, 1965, p. 488).

Apparently, $\mathrm{H} 1, \mathrm{H} 2$, and $\mathrm{H} 3$ cannot be all true: if understanding is pragmatic/relativistic, and whether a scientific explanation is good is a nonpragmatic/objective issue, then it is not the case that a good scientific explanation is the one that provides understanding. So, Hempel seems inconsistent. Call it the "Hempel puzzle."

There have been two responses to this puzzle. On the one hand, some philosophers suggest that Hempel is indeed inconsistent. For instance, Trout (2002, p. 217) thinks while Hempel is a trenchantly objectivist (in that he holds both $\mathrm{H} 1$ and $\mathrm{H} 2$ ), he is "tempted by the allure of internal access" and thereby endorses $\mathrm{H} 3$. Yet $\mathrm{H} 1, \mathrm{H} 2$, and $\mathrm{H} 3$ cannot be all true.
On the other, some philosophers (e.g., Baumberger, Beisbart, Brun, \& Christoph Baumberger, 2017, de Regt, 2009a, b; 2017) agree that H1, $\mathrm{H} 2$, and $\mathrm{H} 3$ cannot be all true, but they claim that Hempel does not actually endorse H3. For example, on Henk W. de Regt's interpretation, Hempel makes a distinction between subjective understanding and objective understanding: "As far as subjective understanding is concerned, Hempel thus reduces it to 'rational expectation.' ... From a philosophical perspective, ...the only legitimate form of scientific understanding is ... objective understanding ..., [which is] nothing else than explanation of phenomena by subsuming them under covering laws" (De Regt, 2017, pp. 49-50). Elsewhere he states, "Insofar as objectivists [like Hempel] are willing to discuss scientific understanding, they identify it with explanation, thereby making it redundant" (de Regt, 2009a, p. 587). If Hempel identifies objective/scientific understanding with scientific explanation, he cannot really hold the view that the goal of scientific explanation is objective/scientific understanding. Nor does Hempel hold that subjective understanding is the goal of scientific explanation according to de Regt, who claims that for Hempel, subjective understanding is pragmatic/relativistic and thus "irrelevant to the philosophy of science" (de Regt, 2009a, p. 586).

In this paper, I will argue, against both responses, that Hempel does hold H3 and may consistently hold all of H1, H2, and H3. My plan is as follows. First, I will argue, pace de Regt et al., that Hempel does not reduce scientific understanding to scientific explanation. Instead, Hempel holds that scientific explanation aims at scientific understanding. Next, I will argue that if Hempel endorses what I call the "understanding argument,"

E-mail addresses: huxingmingpku@gmail.com,xingminghu@nju.edu.cn. 
then he can consistently hold all of $\mathrm{H} 1, \mathrm{H} 2$, and $\mathrm{H} 3$, and accordingly, the Hempel puzzle is dissolved. Finally, I will provide two further reasons why Hempel ought to endorse the understanding argument: (a) Endorsing this argument can help Hempel explain why his D-N model states necessary and sufficient conditions for good scientific explanation. In particular, it can help Hempel address some classic objections to the D-N model. (b) The understanding argument can make more sense of Hempel's philosophical analysis of the pragmatic aspects of scientific explanation.

\section{Understanding as the goal of explanation}

On Hempel's view, an explanation consists of two parts: the explanandum and the explanans. An explanandum is a sentence describing the phenomenon to be explained, and the explanans are the sentences adduced as explanations of that phenomenon. Consider the following explanation: (P) Baby Jane has Down's Syndrome because (B) her cells have three copies of chromosome 21, and (L) any infant whose cells have three copies of chromosome 21 has Down's Syndrome. P is the explanandum. B and L are the explanans.

Hempel explicitly and repeatedly states that scientific explanation aims at understanding. As we have seen above, he says, "All scientific explanation ... seeks to provide a systematic understanding of empirical phenomena by showing that they fit into a nomic nexus" (Hempel, 1965, p. 488). Here are a few more passages where he makes the same point:

- What scientific explanation ... aims at is ... an objective kind of insight that is achieved by a systematic unification, by exhibiting the phenomena as manifestations of common underlying structures and processes that conform to specific, testable, basic principles (Hempel, 1966, p. 83).

- Scientific explanation is not aimed at creating a sense of familiarity with the explanandum; "reduction to the familiar" is at best an incidental aspect of it. The understanding it conveys lies rather in the insight that the explanandum fits into, or can be subsumed under, a system of uniformities represented by empirical laws or theoretical principles (Hempel, 1965, p. 488).

- A class of phenomena has been scientifically understood to the extent that they can be fitted into a testable, and adequately confirmed, theory or a system of laws; and the merits of functional analysis [which is a kind of scientific explanation often employed in biology and psychology] will eventually have to be judged by its ability to lead to this kind of understanding (Hempel, 1965, p. 329).

In these passages, Hempel claims that the goal of scientific explanation is scientific understanding: Whether a scientific explanation is good depends on whether it can lead to scientific understanding. For him, scientific understanding is not a sense of familiarity, ${ }^{1}$ but an insight consisting in seeing the phenomenon in question as an instance of a general pattern described by certain well-tested empirical laws (or the socalled laws of nature). As Hempel (1965: 257) puts it, "Understanding in the theoretical, or cognitive, sense [involves] exhibiting the phenomenon to be explained as a special case of some general regularity." Reconsider the explanation of why (P) Baby Jane has Down's Syndrome: It is because (B) her cells have three copies of chromosome 21, and (L) any infant whose cells have three copies of chromosome 21 has Down's Syndrome. This explanation can help us see the phenomenon that $\mathrm{P}$ as a special instance of a general pattern described by the law $\mathrm{L}$ by providing the information that B and L. ${ }^{2}$ Put differently, this explanation can help us

\footnotetext{
${ }^{1}$ As Hempel (1965, p. 432) nicely put it, "familiarity breeds content, but no insight."

${ }^{2}$ Hempel may say - though he does not actually say - that seeing the phenomenon as a special instance of a general pattern requires having relevant true beliefs and grasping the law describing the general pattern, and to grasp a law is to be able to apply the law to various contexts. This view is very similar to some accounts of understanding in recent literature (for a survey, see Grimm, 2010b).
}

acquire scientific understanding. [To be sure, one must have a prepared mind in order to employ such an explanation to achieve scientific understanding. I will discuss this issue later.]

In addition, Hempel claims scientific understanding consists in rational expectation. He writes, "Given particular circumstances and the laws in question, the occurrence of the phenomenon was to be expected; and it is in this sense that the explanation enables us to understand why the phenomenon occurred" (Hempel, 1965, p. 337). Though Hempel does not make it explicit, the idea that scientific understanding consists in rational expectation seems to logically follow from the idea that scientific understanding consists in seeing the phenomenon in question as an instance of a general pattern in nature. Reconsider the Baby Jane case. If through following the explanation, one sees the phenomenon that $\mathrm{P}$ as a special instance of a general pattern described by the law $L$, then one not only knows that the particular circumstance $\mathrm{B}$ and the law $\mathrm{L}$ but also sees how given B, P would necessarily occur in light of L, and consequently, one would rationally expect the occurrence of $P$.

To sum up, Hempel's account of scientific understanding is different from his account of scientific explanation. On his view, scientific understanding is a psychological state of great epistemic value: It is an insight. It consists in seeing the phenomenon in question as an instance of a general pattern as well as rationally expecting the phenomenon (the former seems to entail the latter). By contrast, a scientific explanation is a set of sentences, not a psychological state. The distinction between scientific understanding and scientific explanation allows him to claim that scientific understanding is the goal of scientific explanation. Peter Lipton (2009, p. 43) thinks "it is more natural to identify understanding with the cognitive benefits that an explanation provides rather than with the explanation itself." Hempel would agree with this view. If so, de Regt's claim (that Hempel identifies scientific understanding with scientific explanation and thereby makes understanding redundant) is false.

\section{Dissolving the Hempel puzzle}

One might object that my interpretation above cannot solve the Hempel puzzle. For if Hempel holds H3, that the goal of scientific explanation is scientific understanding and that a scientific explanation is to be evaluated in terms of this goal, then he must deny $\mathrm{H} 2$, that whether a scientific explanation is good, just like whether a mathematical proof is good, is an objective and nonpragmatic issue. He must deny it because he endorses $\mathrm{H1}$, that scientific understanding is pragmatic/relativistic. More specifically, one scientifically understands why $\mathrm{P}$ happened in terms of Explanation $E$ just in case $E$ enables one to see $P$ as an instance of a general pattern in nature and to rationally expect $\mathrm{P}$. Now whether $\mathrm{E}$ would enable one to see $\mathrm{P}$ as an instance of a general pattern in nature and to rationally expect $\mathrm{P}$ depends on whether one has a prepared mind. Put differently, in order to achieve scientific understanding in terms of $\mathrm{E}$, the mind must process the explanation in an appropriate way. If one cannot follow E (e.g., one cannot understand what some propositions constituting E say or see how the explanandum and explanans of $\mathrm{E}$ are connected), then $\mathrm{E}$ would fail to enable one to see $\mathrm{P}$ as an instance of a general pattern in nature and to rationally expect $P$. Thus, scientific understanding is pragmatic/relativistic: A scientific explanation that enables S1 to scientifically understand might fail to enable S2 to understand.

However, this objection is untenable because from the claim that a scientific explanation is to be evaluated in terms of scientific understanding (which is pragmatic/relativistic), it does not necessarily follow that whether a scientific explanation is good is a purely pragmatic/ relativistic issue. To see this, consider the following argument:

a. While the goal of scientific explanation is to provide understanding, we may further distinguish between two different goals of scientific explanation: the ideal goal is to provide scientific understanding to ideal scientists, and the practical goal is to provide scientific understanding to real individuals including real scientists. In order for a 
person to achieve scientific understanding in terms of a certain explanation, the person must stand in an appropriate epistemic relation to the explanation (cf. Grimm, 2010a; Khalifa, 2017; Strevens, 2013). Put differently, the person must have a prepared mind. Ideal scientists are the people who have a prepared mind: (a) They can tell whether each proposition in the explanation in question is true; (b) They can grasp the explanation in the following sense: They are able to (b1) see whether the explanandum (deductively or inductively) follows from the explanans and (b2) to apply the theory (esp. the general statements that are supposed to describe laws) involved in the explanation to various contexts; (c) Before hearing the explanation, they are puzzled by the question of why the explanandum is the case.

b. While scientific understanding is pragmatic/relativistic, it is not pragmatic/relativistic among ideal scientists: For any two such scientists S1 and S2, an explanation that makes S1 understand would also be able to make S2 understand.

c. An explanation is good iff it achieves the goal of explanation, yet a scientific explanation is good in a nonpragmatic/objective sense just in case it achieves the ideal goal: it would enable ideal scientists to understand why the explanandum is the case (Compare van Inwagen's (2006) definition of objectively good argument in terms of ideal audience).

d. Therefore, from the claim that a scientific explanation is to be evaluated in terms of scientific understanding (which is pragmatic/relativistic), it does not necessarily follow that whether a scientific explanation is good is a purely pragmatic/relativistic issue.

Call this the understanding argument. To be sure, Hempel never straightforwardly makes this argument: He never draws an explicit distinction between the ideal goal and the practical goal of scientific explanation (though he seems to suggest such a distinction when (Hempel, 1965, p. 426) writes, "This ideal intent suggests the problem of constructing a nonpragmatic concept of scientific explanation"), and he never employs the concept of "ideal scientists" to make sense what he calls "scientific/objective understanding." Yet endorsing the understanding argument would make Hempel's account of scientific explanation and understanding more coherent: By endorsing this argument, Hempel can consistently hold $\mathrm{H} 1, \mathrm{H} 2$, and $\mathrm{H} 3$, and accordingly, the Hempel puzzle is dissolved. Moreover, as I shall argue in Section $3 \& 4$, the understanding argument would also make more sense of Hempel's D-N model and his analysis of the pragmatic aspects of scientific explanation.

\section{The D-N model}

In this section, I will show that if Hempel endorses the understanding argument, his D-N model would make more sense. James Woodward (1984, p. 233) claims that a theory of explanation "ought to identify the structural features of such explanation which function so as to produce understanding in the ordinary user." I will argue that Hempel's theory of explanation - the D-N model - can be interpreted as one that identifies "the structural features of such explanation which function so as to produce understanding" in the ideal scientists. ${ }^{3}$ Thus interpreted, Hempel would be in a better position to explain why the D-N model describes necessary and sufficient conditions and thereby to address some classic objections to the model.

Before turning to the arguments, a brief introduction to the D-N

\footnotetext{
3 To be sure, de Regt also notes that the D-N model is related to a conception of understanding based on unification, as he writes, "a scientific explanation of a phenomenon provides understanding because it allows us to see the phenomenon as an instance of a general pattern, rather than as merely an isolated event" (De Regt, 2017, p. 51). Still, he insists that Hempel excludes the psychological elements of scientific understanding (i.e., expecting and seeing) and identifies it with explanation.
}

model is in order. Hempel claims that a good scientific explanation must satisfy the following four conditions:

- (R-1): It must take a form of deductively valid or inductively strong argument;

- (R-2): The explanans must contain general laws, which are required to satisfy R-1;

- (R-3): The explanans must have empirical content and must be testable;

- (R-4): The sentences of the explanans must be true (Hempel, 1965, pp. 247-248).

This is known as the D-N model. ${ }^{4}$ Reconsider the explanation: (P) Baby Jane has Down's Syndrome because (B) her cells have three copies of chromosome 21, and (L) any infant whose cells have three copies of chromosome 21 has Down's Syndrome. Suppose B and L are both true. Then this explanation meets all four conditions. So, it is a good scientific explanation according to the D-N model.

\subsection{Why the $D-N$ model describes necessary conditions}

Hempel holds that each of the four conditions R1-R4 of the D-N model is necessary for good scientific explanation. But why are they necessary? For instance, why must a good scientific explanation invoke general laws? Hempel provides no answer. I will argue that endorsing the understanding can help Hempel answer this question: An explanation that fails to meet any of the four conditions cannot enable us to achieve scientific understanding.

First, according to the D-N model, a good scientific explanation must satisfy R-1 - it must take a form of deductively valid or inductively strong argument - because if it is neither deductively valid nor inductively strong, then we cannot rationally expect the explanandum-phenomenon on the basis of the explanans. But scientific understanding (in terms of a certain scientific explanation) consists in rationally expecting the phenomenon on the basis of the explanans (as well as seeing the phenomenon in question as an instance of a general pattern). Thus, if an explanation is neither deductively valid nor inductively strong, then we cannot achieve scientific understanding through following the explanation.

Second, the D-N model requires R-2, that the explanans must contain general laws, for general laws describe general patterns in nature. If an explanation does not contain any general laws, then it cannot enable us to see the phenomenon in question as an instance of a general pattern, and thereby we cannot achieve scientific understanding through following the explanation.

Justifying R2 in terms of scientific understanding can help Hempel address the classic objection that some good explanations do not involve any general laws. Consider the following case originally provided by Michael Scriven:

INK: As you reach for the dictionary, your knee catches the edge of the table and thus turns over the ink-bottle, the contents of which proceed to run over the table's edge and ruin the carpet. If you are subsequently asked to explain how the carpet was damaged you have a complete explanation. You did it, by knocking over the ink. The certainty of this explanation is primeval. It has absolutely nothing to do with your knowledge of the relevant laws of physics; a cave-man could supply the same account and be quite as certain of it (Quoted from Hempel, 1965, p. 360).

\footnotetext{
${ }^{4}$ Hempel calls his account of scientific explanation the "covering laws models of explanation." He distinguishes between three models, i.e., the deductivenomological model, the inductive-statistical model, and the deductive statistical model. Following the convention, I will call Hempel's account of scientific explanation the D-N model for short.
} 
Hempel responds that this case is not a counterexample to his D-N model, because the explanation - that the carpet was stained because the table, with an open bottle of ink standing on it, was caught and lifted by my knee - "might be paraphrased by saying that there are laws connecting the presence of an ink stain on the rug with certain antecedent circumstances, which include an open bottle of ink standing on the table, and the fact that the table's edge was lifted" (Hempel, 1965, pp. 361-362). This response makes some sense, but it does not answer why laws are necessary for a good explanation: The fact that the explanation can be paraphrased in terms of laws does not show that laws are necessary to make the explanation good.

Endorsing the understanding argument can help Hempel answer this question: Laws are necessary for a good scientific explanation because scientific explanation aims at scientific understanding, which consists in seeing the phenomenon in question as an instance of a general pattern described by the laws. If an explanation does not involve any laws, then it does not refer to any general pattern in nature, and accordingly, it cannot enable us to see the phenomenon in question as an instance of a general pattern.

This answer does not imply that all good explanations involve laws, for it does not say that only scientific explanations are good. It allows the possibility that some non-scientific explanations that do not involve laws are good. Thus, it is better for Hempel to say that if the explanation in the INK is supposed to be a good scientific explanation, then it must be capable of being paraphrased in terms of laws, "for scientific research seeks to account for empirical phenomena by means of laws" (Hempel, 1965, p. 426). But if it is supposed to be a good non-scientific explanation that a cave-man can give, then the fact that it does not involve laws poses no challenge to the D-N model, which is an account of good scientific explanation.

Third, the D-N model requires R-3, that the explanans must have empirical content and must be capable of test, because if the explanans does not have empirical content or is untestable, then no observation statements can be deduced or induced from the explanans. ${ }^{5}$ If no observation statements can be deduced or induced from the explanans, then we cannot rationally expect any phenomenon on the basis of the explanans, and thereby we cannot achieve scientific understanding through following the explanation.

Finally, on the D-N model, the sentences of the explanans must be true, because scientific understanding is factive. The explanans consists of a set of statements describing the relevant general laws and background conditions. If the statements describing the general laws are not even approximately true, then the general pattern does not exist, and accordingly, the explanation fails to show that the phenomenon in question is an instance of a general pattern in nature. If the statements describing the general laws are true (i.e., the general pattern exists), but the statements describing the background conditions are false, then the explanation also fails to show that the phenomenon in question instantiates a general pattern. ${ }^{6}$

\subsection{Why the D-N model describes sufficient conditions}

Hempel holds that the D-N model describes not only necessary conditions for good scientific explanation but also sufficient conditions. Why does he think the D-N model describes sufficient conditions? Again, Hempel provides no straightforward answer. I argue that endorsing the understanding can help Hempel answer this question. A

\footnotetext{
5 James Fetzer (2017) notes, "Hempel recognized that (R-3) was a redundant condition, since it would have to be satisfied by any explanation that satisfied (R-1) and (R-2). Insofar as the explanandum describes an event that occurred during the history of the world, its derivation thereby implies the explanans has empirical content."

${ }^{6}$ Clearly, Hempel is not an instrumentalist. For an interesting instrumentalist account of scientific understanding, see Rowbottom (2019).
}

scientific explanation can be objectively good in the sense that it will enable all ideal scientists to achieve scientific understanding. The four conditions of the D-N model are sufficient for an objectively good scientific explanation, because any explanation meeting the four conditions will enable all ideal scientists to achieve scientific understanding. More specifically, ideal scientists are able to grasp a D-N explanation and recognize that the explanans are all true. Thus, a D-N explanation will enable them to see the explanandum as an instance of a general pattern as well as rationally expect the explanandum. Put differently, they can achieve scientific understanding through following a D-N explanation.

In what follows, I will show that endorsing the understanding can also help Hempel address two classic objections to the claim that the D-N model describes sufficient conditions for good scientific explanation.

\subsubsection{Objection 1}

FLAGPOLE: One can derive the length $l$ of the shadow cast by a flagpole from the conjunction of the following three things: the height $h$ of the pole, the angle $\theta$ of the sun above the horizon, and the law of the rectilinear propagation of light. On the other hand, one can also derive $h$ from $l$ and $\theta$ and the same law. Both derivations meet the DN criteria. While the former seems explanatory, the latter does not seem so (Bromberger, 1966).

\subsubsection{Analysis}

FLAGPOLE is widely regarded as a counterexample to the claim that the D-N model describes sufficient conditions for good scientific explanation. As Marc Lange (2016, p. 233) notes, "there is widespread agreement that various other arguments are not explanatory—examples so standard that I need only give their familiar monikers, such as "the flagpole'." Lange seems to suggest that any good account of explanation must respect our intuition that the derivation of the height of the flagpole is not an explanation. But apparently, the D-N model implies that the derivation of the height of the flagpole is a good scientific explanation.

In fact, Hempel expects this objection when he discusses an example similar to FLAGPOLE:

PENDULUM: The law for the simple pendulum makes it possible not only to infer the period of a pendulum from its length, but also conversely to infer its length from its period; in either case, the inference is of the form (D-N). Yet a sentence stating the length of a given pendulum, in conjunction with the law, will be much more readily regarded as explaining the pendulum's period than a sentence stating the period, in conjunction with the law, would be considered as explaining the pendulum's length (Hempel, 1965, pp. 352-353).

Hempel offers a debunking explanation why people have the intuition that the derivation of the pendulum's length does not explain: It is because people are more familiar with causal explanations - the explanations that "exhibit the explanandum event as having been brought about by earlier occurrences" - so that they believe "no event can be said to have been brought about by factors some of which were not even realized at the time of its occurrence" (Hempel, 1965, p. 353). Given this belief, people tend to think that if $\mathrm{X}$ and $\mathrm{Y}$ are simultaneous, or $\mathrm{X}$ happened after $\mathrm{Y}$, then $\mathrm{X}$ does not explain $\mathrm{Y}$.

Hempel agrees that if $\mathrm{X}$ and $\mathrm{Y}$ are simultaneous, or $\mathrm{X}$ happened after $\mathrm{Y}$, then $\mathrm{X}$ does not causally explain $\mathrm{Y}$, but he does not think it necessarily follows that $\mathrm{X}$ does not explain $\mathrm{Y}$, for not all explanations are causal. Hempel (1962, p. 12) writes, "Causal explanation is deductive-nomological in character .... The converse does not hold: there are deductive-nomological explanations which would not normally be counted as causal." He distinguishes between two kinds of non-causal explanations that fit the D-N model. First, the explanandum of a D-N explanation might be a law. Hempel thinks the subsumption of laws, such as Galileo's or Kepler's laws, under more comprehensive laws is "clearly 
not causal in character: we speak of causes only in reference to particular facts or events, and not in reference to universal facts as expressed by general laws" (Hempel, 1962, p. 12). Second, Hempel (1965: 352) claims that "even when used to account for individual events, D-N explanations are not always causal."7 Here is one of several examples he offers:

For example, the fact that a given simple pendulum takes $2 \mathrm{~s}$ to complete one full swing might be explained by pointing out that its length is $100 \mathrm{~cm}$, and that the period $\mathrm{t}$ (in seconds), of any simple pendulum is connected with its length 1 (in centimeters) by the law that $t=2 \pi \sqrt{ } 1 / g$, where $g$ is the acceleration of free fall. (ibid.)

Hempel thinks this is a mathematical explanation rather than a causal explanation. For causal explanation presupposes laws of succession, which concern temporal changes in a system. But the law that $t=2 \pi \sqrt{ } 1 / g$ "expresses a mathematical relationship between the length and the period (which is a quantitative dispositional characteristic) of the pendulum at one and the same time" (ibid.). Laws of this kind are called laws of coexistence. Clearly, in the case of the pendulum, only a law of coexistence is invoked, so "one surely would not say that the pendulum's having a period of $2 \mathrm{~s}$ was caused by the fact that it had a length of $100 \mathrm{~cm}$ " (ibid.). ${ }^{8}$

In light of the above analysis, Hempel would say that the FLAGPOLE is not a counterexample to the D-N model, because our intuition that the derivation of the height of the flagpole is not an explanation is unreliable. This intuition comes from our belief that all explanations are causal and that the length of the shadow of the flagpole does not causally explain its height. But the belief that all explanations are causal is false. It is worth noting some philosophers (e.g., De Regt \& Dieks, 2005) offer a similar debunking explanation of the FLAGPOLE. ${ }^{9}$

Given Hempel's debunking explanation of the intuition, he would provide the following analysis though he never makes it explicit: the FLAGPOLE can be interpreted in two ways. First, one might ask a causal question: Why was this flagpole made $h$ feet tall? Second, one might literally ask a geometrical and thus non-causal question: Given that the flagpole has a height, and space is Euclidean, why is the measure of the height $h$ feet? If one asks the causal question, then clearly the derivation of the height of the pole is not an explanation. But if one asks the geometrical question, then it is plausible to say the derivation of the height of the pole is an explanation (cf. Levin \& Levin, 1977, p. 294).

However, one might object that even though some explanations are non-causal, it does not follow that the derivation of the height of the pole

\footnotetext{
${ }^{7}$ It is worth noting that while some philosophers (e.g., Salmon, 1984 and Lewis, 1986) hold that no explanations of particular events are non-causal, recently, few philosophers have affirmed this view, as Bradford Skow (2014) notes. Rather, many philosophers hold that some explanations of particular events are non-causal (cf. Reutlinger and Saatsi, 2018). Skow (2014) attempts to swim against the current. But Finnur Dellsen (2016) argues that Skow's arguments fail. In his book Because Without Cause, Marc Lange (2016) proposes philosophical accounts of many kinds of non-causal explanations in science and mathematics.

${ }^{8}$ Thus, Jaegwon Kim (2010, p. 195) does not get Hempel right when he writes, "In fact, we can think of Hempel's D-N model of explanation (when applied to individual events) as giving a sort of Humean nomological analysis of causal relations."

9 For example, De Regt and Dieks (2005, p. 164) writes, "We hold that it depends on the context whether the length of the flagpole makes it understandable how long the shadow is, or vice versa. ... ... The commonsense intuition of asymmetry is based upon a preference for everyday causal reasoning" that "singles out earlier events as the causes of what happens later." Like Hempel, de Regt and Dieks find this intuition misleading, for "causal explanations do not possess a unique position in modern science," and "even if preference is given to causal reasoning, physical science does not automatically fit in with everyday causal thinking and does not always single out earlier events as the causes of what happens later" (ibid.). De Regt and Dieks agree with van Fraassen that in particular contexts the length of the flagpole can be explained by the length of the shadow (van Fraassen, 1980, pp. 130-134).
}

in the FLAGPOLE (as well as the derivation of the pendulum's length in the PENDULUM) is a non-causal explanation. As I noted earlier, Marc Lange (2016) suggests that any good account of explanation must respect people's intuition that the derivation of the height of the flagpole is not an explanation, though he argues that there are mathematical explanations that are non-causal.

Hempel's response is twofold. First, he considers some arguments for the view that the derivation of the pendulum's length in PENDULUM does not explain why the pendulum is of a certain length, and he contends that these arguments are fallacious (Hempel, 1965, pp. 352-353). I will not rehearse these arguments and Hempel's rebuttals here, for they are complicated and not relevant to the goal of this section.

Second, Hempel suggests an account of what makes a derivation/ inference explanatory: "The laws connect the explanandum event with the particular conditions cited in the explanans, and this is what confers upon the latter the status of explanatory (and, in some cases, causal) factors in regard to the phenomenon to be explained" (Hempel, 1962, p. 12). He makes a similar point in Aspects (1965: 425). Here, Hempel seems to think that if an argument shows that an individual event is an instance of a general pattern described by the laws, then it is explanatory.

While Hempel offers no explicit argument for this view, endorsing the understanding argument can help him make a case for the view. Specifically, Hempel may argue as follows:

1. Scientific understanding without explanation is impossible.

2. Therefore, if $X$ by itself would enable someone to achieve scientific understanding, then $\mathrm{X}$ must be explanatory.

3. Scientific understanding consists in seeing the phenomenon in question as an instance of a general pattern.

4. Therefore, if an argument shows that an individual event is an instance of a general pattern, then it would enable ideal scientists to achieve scientific understanding.

5. Therefore, if an argument shows that an individual event is an instance of a general pattern, then it must be explanatory.

While Premise 1 is controversial (cf. Lipton, 2009), it is not indefensible. In fact, some philosophers (e.g., Khalifa, 2017; Strevens, 2013) explicitly defend such a view. And some philosophers (e.g., De Regt \& Dieks, 2005, p. 164) seem to endorse the idea that all understanding-providing arguments are explanatory.

Given the above argument, all D-N arguments concerning an individual event are (causally or non-causally) explanatory since they all provide understanding by showing that an individual event is an instance of a general pattern. Thus, neither the FLAGPOLE nor the PENDULUM is a counterexample.

\subsubsection{Objection 2}

PREGNANCY: All males who take birth control pills regularly fail to get pregnant. John Jones is a male who has been taking birth control pills regularly. That is why John Jones fails to get pregnant. This reasoning meets the DN criteria but does not seem explanatory (Salmon, 1971).

\subsubsection{Analysis}

Hempel would say PREGNANCY fails to meet the D-N criteria because it does not involve a genuine law. A genuine law is required for a good scientific explanation because, as we have seen in Section 3.1, the goal of scientific explanation is scientific understanding, which involves seeing a phenomenon as an instance of a general pattern in nature, and a general pattern in nature is described by a genuine law. Thus, if an explanation does not contain any genuine laws, then it cannot enable us to see the phenomenon in question as an instance of a general pattern, and thereby we cannot achieve scientific understanding through grasping the explanation. Now intuitively, the statement that all males who take birth control pills regularly fail to get pregnant is not 
a genuine law: It does not describe a general pattern in nature (while "no males can get pregnant" is a genuine law describing a general pattern in nature).

In fact, Hempel (1965: 338-342) notes that there is an intuitive distinction between lawlike sentences (which states genuine laws) and non-lawlike generalizations (which does not state genuine laws). And he thinks "giving a clear characterization of lawlike sentences" is an "important and intriguing" problem, but "this problem has proved to be highly recalcitrant" (Hempel, 1965, p. 338). He says he can only provide "a few observations on certain aspects of it that are relevant also to the analysis of scientific explanation" (ibid). Unfortunately, his "observations" are just a bunch of objections to certain accounts of lawlike sentences proposed by Nelson Goodman and others. He does not propose any positive account.

But this does not show that his D-N model is false. It merely shows that it is incomplete, as Woodward (2019, Section 2.2) says, providing an account of genuine laws is "an important item of unfinished business for advocates of the DN model."

\section{The pragmatic aspects of scientific explanation}

In the previous section, I argued that the understanding argument can shed light on Hempel's account of the nonpragmatic aspects of scientific explanation. In this section, I will argue that the understanding argument can make more sense of Hempel's analysis of the pragmatic aspects of scientific explanation. According to de Regt, "Hempel claims that understanding belongs to the pragmatic dimension of science, which is irrelevant to the philosophical analysis of science" and "should be ignored by philosophers" (De Regt, 2017, pp. 16-17). Pace de Regt, I will first argue that Hempel does not dismiss the pragmatic dimension of science as irrelevant to the philosophical analysis of science: In fact, Hempel actually gives a philosophical analysis of some pragmatic aspects of scientific explanation. Then I will show that endorsing the understanding argument can help Hempel explain why a philosophical analysis of the pragmatic aspects of scientific explanation is necessary and important. Finally, I will close this section by suggesting that Hempel would agree with de Regt that what de Regt calls pragmatic understanding is philosophically important.

To begin with, Hempel never claims that the pragmatic aspects of science are philosophically irrelevant. He merely argues that a significant and nonpragmatic account of scientific explanation is possible in response to the following objection to the $\mathrm{D}-\mathrm{N}$ model:

\section{All explanations including scientific explanations are inherently pragmatic.}

2. If 1 , then any account of scientific explanation that does not take into account its pragmatic aspects is hopelessly inadequate.

3. The D-N model fails to take into account the pragmatic aspects of scientific explanation.

4. Therefore, the D-N model is hopelessly inadequate.

Hempel accepts Premise 1 of this objection. He writes, "Very broadly speaking, to explain something to a person is to make it plain and intelligible to him, to make him understand it. Thus construed, the word 'explanation' and its cognates are pragmatic terms: their use requires reference to the persons involved in the process of explaining" (Hempel, 1965, p. 425).

But Hempel explicitly rejects Premise 2, as he writes,

To call attention to the important pragmatic facets of explanation and to indicate the diverse procedures that may be appropriate in different cases to dispel the perplexity reflected in someone's quest for an explanation is not to show that a nonpragmatic model of scientific explanation must be hopelessly inadequate, just as analogous arguments concerning the notion of proof cannot show that nonpragmatic models of proof must be sterile and unilluminating. As is well known, the contrary is the case (Hempel, 1965, p. 427, my italics).
Here Hempel suggests that a significant nonpragmatic model of scientific explanation is possible, for scientific explanation is similar to mathematical proof, and a significant nonpragmatic model of mathematical proof is clearly possible. But this analogical argument does not show how it is possible.

As I have shown in the previous sections, endorsing the understanding argument can help Hempel explain how it is possible. While all explanations, including scientific explanations, are inherently pragmatic/relativistic in a sense, there is another sense in which some scientific explanations are not pragmatic/relativistic: they are good in that they would enable ideal scientists to achieve scientific understanding, and for any two such scientists S1 and S2, an explanation that makes S1 understand would also be able to make S2 understand.

In addition, Hempel (1965, pp. 426-427) emphasizes that to propose a nonpragmatic model of scientific explanation is "neither to deny the pragmatic 'dimension' of explanation nor to belittle its importance; nor, of course, is it to claim that people will find an explanatory account illuminating or satisfactory only as far as it conforms to one of the covering-law models." Moreover, Hempel explicitly acknowledges that most explanations working scientists actually give are pragmatic, for working scientists formulate their explanations "with a particular kind of audience-and thus with particular pragmatic requirements - in mind. This is true also of the way in which mathematicians present their proofs" (Hempel, 1965, p. 428). It is unlikely that he would dismiss most explanations working scientists actually give as irreverent to philosophical analysis of science.

In fact, Hempel himself gives a philosophical analysis of some pragmatic aspects of scientific explanation. For example, following William Dray, Hempel (1965, p. 428) draws a distinction between explaining why-necessarily an event occurred and explaining how-possibly an event could have occurred. He argues that while a D-N explanation might be adequate for explaining why-necessarily an event occurred; to explain how-possibly an event could have occurred is quite a different task, which concerns important pragmatic aspects of explanation. Here is one of the examples Hempel provides: If a friend tells me that his teaspoon promptly melted when he put it into a cup of hot punch, I might ask: how could this possibly have happened - metal does not melt at so low a temperature? On Hempel's analysis, we normally ask how X could possibly have occurred only if some of the beliefs we hold make it impossible, or at least highly improbable, that $\mathrm{X}$ should have occurred. Accordingly, to give an adequate "how-possible" explanation, it will be necessary to "ascertain the empirical assumptions underlying the question and then to show either that some of these are false or else that the questioner was mistaken in thinking that those assumptions warranted his belief that $\mathrm{X}$ could not have occurred" (Hempel, 1965, p. 428). Thus, in the teaspoon case, I ask the how-possible question because I probably hold the false belief that no metals will melt at the temperature of hot punch. So, if you point out that some metals, such as Wood's alloy, do melt at the temperature of hot punch, and that the teaspoon in question had indeed been one of those made from Wood's alloy, then you are giving me an adequate how-possible explanation. [Hempel notes that a similar analysis applies to the questions taking the form "Why is it not the case that p?" People sometimes ask questions like "Why doesn't the Leaning Tower of Pisa topple over?", "Why don't the antipodes fall off the earth?", or "If reflection in a plane mirror interchanges right and left, why not also top and bottom?" Hempel thinks all these questions might well be rephrased as how-possible questions: "How could it possibly be the case that not-p?"]

Admittedly, Hempel emphasizes that an adequate pragmatic explanation (e.g., a how-possible explanation) must address the questioner's psychology. But his analysis is philosophical rather than purely psychological, for according to his analysis, a scientific explanation addressing a how-possible question is adequate not simply because the audience asking the question finds it psychologically satisfactory. Instead, as I noted above, Hempel thinks to give an adequate how-possible explanation, it will be necessary to "ascertain the empirical assumptions 
underlying the question and then to show either that some of these are false or else that the questioner was mistaken in thinking that those assumptions warranted his belief that X could not have occurred" (Hempel, 1965, p. 428). These are objective necessary conditions for adequate how-possible explanation, for whether an assumption is true and whether a set of assumptions warrants (inductively support or deductively entail) a certain belief are objective issues. ${ }^{10}$

Hempel does not explain why pragmatic scientific explanations must also satisfy some objective conditions. Endorsing the understanding argument would help him answer this question. Specifically, there are two goals of scientific explanation: the ideal goal is to provide scientific understanding to ideal scientists, and the practical goal is to provide scientific understanding to real individuals (including real scientists). As the ideal goal, scientific understanding is non-pragmatic/objective in the sense that an explanation that enables an ideal scientist to acquire scientific understanding will also enable other ideal scientists to acquire scientific understanding. As the practical goal, scientific understanding is pragmatic/relativistic in the sense that an explanation that enables a real individual to acquire scientific understanding might fail to enable another real individual to acquire scientific understanding. Yet pragmatic/relativistic understanding and non-pragmatic/objective understanding have the same content: it is a psychological state of great epistemic value. Now all pragmatic scientific explanations (e.g., a how-possible explanation) aim at providing scientific understanding to real individuals. They are to be epistemically evaluated in terms of this goal. While individuals differ in their beliefs and cognitive abilities, as long as they achieve a scientific understanding of a certain phenomenon, their understanding is factive, for it consists in seeing the phenomenon as an instance of a general pattern. If an individual has false beliefs about a general pattern or about how the phenomenon in question instantiates a general pattern, then she cannot really see the phenomenon as an instance of the general pattern. Thus, a pragmatic scientific explanation must satisfy some objective conditions in order for the individual who grasps (and assent to) the explanation to achieve scientific understanding.

In addition, endorsing the understanding argument would also make more sense of Hempel's view that all adequate pragmatic scientific explanations implicitly presuppose a D-N explanation (Hempel, 1965, pp. 424-425). It is because every adequate pragmatic scientific explanation can enable some real individuals to achieve scientific understanding, which consists in the phenomenon in question as an instance of a general pattern. If a pragmatic scientific explanation does not implicitly presuppose a D-N explanation, then it cannot enable any real individuals to achieve scientific understanding.

Before closing this section, I'd like to suggest Hempel would also agree with de Regt that what de Regt calls pragmatic understanding is philosophically important. De Regt (2009a, p. 588) makes a distinction between three different ways in which the term "understanding" can be used in connection with scientific explanation:

- FU: feeling of understanding $\mathrm{p}=$ the subjective psychological experiences accompanying an explanation.

- UT: understanding a theory $\mathrm{p}=$ being able to use the theory (pragmatic understanding).

- UP: understanding a phenomenon $\mathrm{p}=$ having an appropriate explanation of the phenomenon.

\footnotetext{
10 To be sure, Hempel makes the following comment on Michael Scriven's account of explanation, "Such expressions as 'realm of understanding' and 'comprehensible' do not belong to the vocabulary of logic, for they refer to the psychological or pragmatic aspects of explanation" (Hempel, 1965, p. 413). But it is unclear what Hempel means by "vocabulary of logic." This comment alone does not support the reading that Hempel thinks philosophers should ignore the pragmatic aspects of explanation. Rather, Hempel's analysis of pragmatic scientific explanations is philosophical because it concerns the question of how to evaluate such explanations from an epistemic point of view, as we shall see.
}

According to de Regt, Hempel holds that both FU and UT belong to pragmatic aspects of science, which he dismisses as irrelevant to philosophy of science. While agreeing with Hempel that FU is philosophically irrelevant, de Regt argues that pragmatic understanding UT is philosophically important, for it is "a crucial condition for reaching the epistemic aim UP" (ibid.). Here is an outline of his argument:

1. Understanding a phenomenon $\mathrm{p}=$ having an appropriate explanation of the phenomenon.

2. To have an appropriate explanation of $\mathrm{p}$, it is not enough to know the relevant laws and the background conditions; it also requires the ability to derive the explanandum $\mathrm{p}$ from the relevant laws and background conditions. For example, de Regt (2009a, p. 588) writes, "merely knowing Bernoulli's principle and the background conditions is not equal to having an explanation: in addition, one should be able to use this knowledge in the right way to derive the explanandum. Thus, a student may have memorized Bernoulli's principle and have all background conditions available but may still be unable to use this knowledge to account for the fact that jets can fly. The extra ingredient needed to construct the explanation is a skill: the ability to construct deductive arguments from the available knowledge."

3. The ability to use a theory (often consisting of a set of general statements describing laws) = the ability to derive the empirical implications from the theory and the relevant background conditions.

4. Therefore, to understand a phenomenon $\mathrm{p}$, one must be able to use the relevant theory. That is, UT is a crucial condition for UP.

I want to suggest that Hempel would endorse de Regt's argument. For Hempel never claims that anyone who is presented with a D-N explanation of $\mathrm{p}$ would automatically understand why $\mathrm{p}$ - he does not identify scientific understanding with D-N explanation, as I argued in Section 1. Instead, he suggests that if one is presented with a D-N explanation of $\mathrm{p}$ but unable to see how the explanandum derives from the explanans, then one would not understand why p. As he writes, in some cases, "the questioner may be aware of the requisite particular data and laws but may need to be shown how the explanandum can be derived from this information" (Hempel, 1965, p. 427). And he adds a footnote here: "the derivation may well present considerable mathematical difficulties and may thus be hard to discover" (ibid.). Thus, Hempel would agree that UT is a crucial condition for UP.

\section{Conclusion}

In summary, Hempel seems to hold three apparently inconsistent views: (H1) understanding is pragmatic/relativistic: Whether one understands why $\mathrm{X}$ happened in terms of Explanation $\mathrm{E}$ depends on one's beliefs and cognitive abilities; (H2) whether a scientific explanation is good, just like whether a mathematical proof is good, is a nonpragmatic and objective issue independent of the beliefs or cognitive abilities of individuals; (H3) the goal of scientific explanation is understanding: A good scientific explanation is one that provides understanding. Some philosophers claim that Hempel is inconsistent, while some other philosophers argue that Hempel does not actually hold H3. By contrast, I have shown that Hempel does hold $\mathrm{H} 3$ and that he can consistently hold all of $\mathrm{H} 1, \mathrm{H} 2$, and $\mathrm{H} 3$ if he endorses the understanding argument. I have also shown how attributing the understanding argument to Hempel can make more sense of his D-N model and his analysis of the pragmatic aspects of scientific explanation. If my analysis is correct, then it is plausible to attribute the understanding argument to Hempel.

\section{Acknowledgements}

Thanks to Stephen Grimm, Wei Wang, Mingyan Yang, Mingjun Zhang, Liqian Zhou, and the students who attended my 2021 graduate seminar on philosophical writing. 


\section{References}

Baumberger, C., Beisbart, C., Brun, G., \& Christoph Baumberger, S. G. (2017). What is understanding? An overview of recent debates in epistemology and philosophy of science. In S. Ammon (Ed.), Explaining understanding: New perspectives from epistemolgy and philosophy of science (pp. 1-34). Routledge.

Bromberger, S. (1966). Why questions. In R. G. Colodney (Ed.), Mind and cosmos (pp. 86-111). Pittsburgh, PA: University of Pittsburgh Press.

De Regt, H. W. (2009a). The epistemic value of understanding. Philosophy of Science, 76(5), 585-597.

De Regt, H. W. (2017). Understanding scientific understanding. Oxford University Press.

De Regt, H. W., \& Dieks, D. (2005). A contextual approach to scientific understanding. Synthese, 144(1), 137-170.

De regt, H. W. (2009b). Understanding and scientific explanation. In H. W. de Regt, S. Leonelli, \& K. Eigner (Eds.), Scientific understanding: Philosophical perspectives. Pittsburgh: University of Pittsburgh Press.

Dellsén, F. (2016). There may yet be non-causal explanations. Journal for General Philosophy of Science / Zeitschrift für Allgemeine Wissenschaftstheorie, 47(2), 377-384.

Fetzer, J. (2017). Carl Hempel. Stanford Encyclopedia of Philosophy.

Grimm, S. R. (2010a). The goal of explanation. Studies in History and Philosophy of Science Part A, 41(4), 337-344.

Grimm, S. R. (2010b). Understanding. In Routledge companion to epistemology (pp. 110-120). Routledge.

Hempel, C. G. (1962). Explanation in science and history. In R. C. Colodny (Ed.), Frontiers of science and philosophy (pp. 9-19). Pittsburgh: The University of Pittsburgh Press.

Hempel, C. G. (1965). Aspects of scientific explanation and other essays in the philosophy of science. New York: Free Press.

Hempel, C. G. (1966). Philosophy of Natural Science. Englewood Cliffs, NJ: Prentice-Hall.

Khalifa, K. (2017). Understanding, explanation, and scientific knowledge. Cambridge, UK: Cambridge University Press.
Kim, J. (2010). Essays in the metaphysics of mind. Oxford University Press.

Lange, M. (2016). Because without cause. Oxford University Press.

Levin, M. E., \& Levin, M. R. (1977). Flagpoles, shadows and deductive explanation. Philosophical Studies, 32(3), 293-299.

Lewis, D. (1986). Causal Explanation. In D. Lewis (Ed.), Vol. II. Philosophical papers (pp. 214-240). New York: Oxford University Press.

Lipton, P. (2009). Understanding without explanation. In H. W. de Regt, S. Leonelli, \& K. Eigner (Eds.), Scientific understanding: Philosophical perspectives (pp. 43-63). University of Pittsburgh Press.

Reutlinger, A., \& Saatsi, J. (Eds.). (2018). Explanation beyond causation: Philosophical perspectives on non-causal explanations. Oxford University Press.

Rowbottom, D. P. (2019). The instrument of science: Scientific anti-realism revitalised. New York: Routledge.

Salmon, W. (1971). Statistical explanation. In W. Salmon (Ed.), Statistical explanation and statistical relevance (pp. 29-87). Pittsburgh: University of Pittsburgh Press.

Salmon, W. (1984). Scientific explanation and the causal structure of the world. Princeton: Princeton University Press.

Skow, B. (2014). Are there non-causal explanations (of particular events)? British Journal for the Philosophy of Science, 65(3), 445-467.

Strevens, M. (2013). No understanding without explanation. Studies in History and Philosophy of Science Part A, 44(3), 510-515.

Trout, J. D. (2002). Scientific explanation and the sense of understanding. Philosophy of Science, 69(2), 212-233.

Van Fraassen Bas, C. (1980). The scientific image. Oxford University Press.

van Inwagen, P. (2006). The problem of evil. Oxford: Oxford University Press.

Woodward, J. (2019). Scientific explanation. In E. N. Zalta (Ed.), The stanford Encyclopedia of philosophy (winter 2019 edition. https://plato.stanford.edu/archives/win2019/ent ries/scientific-explanation/.

Woodward, J. (1984). A theory of singular causal explanation. Erkenntnis, 21(3), 231-262. 